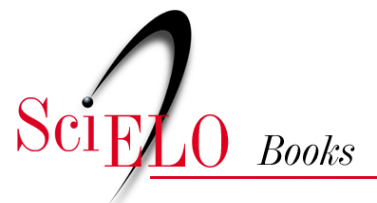

\title{
5. Comentários (médicos sobre a experiência antropológica em campo e o tema dos nervos
}

\author{
Maria Lucia da Silveira
}

\section{SciELO Books / SciELO Livros / SciELO Libros}

SILVEIRA, M. L. Comentários (médicos sobre a experiência antropológica em campo e o tema dos nervos. In: O nervo cala, o nervo fala: a linguagem da doença [online]. Rio de Janeiro: Editora FIOCRUZ, 2000. Antropologia e saúde collection, pp. 95-98. ISBN: 978-85-7541-609-9. Available from: doi: $10.7476 / 9788575416099.006$. Also available in ePUB from: http://books.scielo.org/id/k4vp7/epub/silveira-9788575416099.epub.

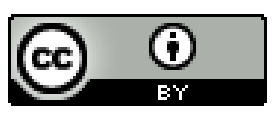

All the contents of this work, except where otherwise noted, is licensed under a Creative Commons Attribution 4.0 International license.

Todo o conteúdo deste trabalho, exceto quando houver ressalva, é publicado sob a licença Creative Commons Atribição 4.0. 


\section{5 \\ Comentários (Médicos) sobre a Experiência Antropológica em Campo e o Tema dos Nervos}

Estudar nervos possibilitou à médica, formada dentro dos limites estreitos de uma prática clínica e científica baseada no paradigma cartesiano, ${ }^{1}$ utilizar recursos metodológicos da antropologia social para a pesquisa de campo e compreender como a antropologia pode servir como uma via para o médico conhecer melhor o seu paciente. Foram necessários, para isso, estranhamentos sucessivos em relação à profissão médica e à minha própria condição de mulher e, eventualmente, de nervosa também.

Entretanto, o esforço parece ter me conduzido a bom resultado, me possibilitando:

- firmar as noções e implicações de gênero;

- perceber como a prática médica está longe de ser satisfatória para os pacientes enquanto permanecer alheia às nuances e aos significados culturais da doença e indiferente ao desencontro de seus próprios códigos com o dos pacientes e de outros especialistas em cura e como, no caso contrário, continuará repetindo os tantos diálogos de surdos que se ouvem por aí;

- ver que não basta ao médico ser bonzinho ou simpático, se o faz sem traduzir estas expressões para formas culturalmente compreensíveis para o paciente;

- perceber que temas como cultura, gênero, estereótipos, preconceitos, representações sociais, linguagem, tabus etc. também têm de fazer parte das discussões clínicas.

O trabalho permitiu, ainda, perceber que a antropologia, por evidenciar as diferenças e permiti-las sem dissimulação, pode facilitar a superação das desigualdades e se constituir num instrumento de encontro. Ela possibilita que o médico, mais do que atender, se relacione com o sujeito que sofre:

É claro que em situações correntes o enfermo acode ao médico não por sua doença mas pelo seu sofrimento, que é o que o preocupa, não só para estabelecer um diagnóstico preciso que lhe sirva de base para o tratamento, mas para atender com eficiência e compreensão as moléstias que constituem seu padecimento. Quando se exerce dessa maneira, que em minha experiência é a regra em lugar da exceção, a Medicina inclui dentro de seus interesses e ações não só o fenômeno biológico 
conhecido como doença, mas o ser humano que a padece e sem o qual o processo patológico não existiria, assim como o nicho social e cultural onde ocorre o episódio. Em outras palavras, no exercício da boa Medicina (grifo do autor), o conceito biomédico não se contrapõe (grifo meu) ao conceito biopsíquico e sociocultural da doença, porém ambos se complementam. (Tamayo, 1988:236)

Porém, se do próprio trabalho foi possível perceber que a abordagem antropológica amplia a análise da doença, em especial a dos nervos, com o deslindar de significados e com o aporte crítico desenredando tramas de poder e manipulação de sujeitos, é preciso ter em mente a advertência feita por Low (1994b) sobre os riscos de abandonar as variáveis biológicas. Se não são as únicas intervenientes no processo saúde/doença, tais variáveis nele têm um peso considerável, por constituírem um elemento de interação e de modulação da ação da cultura sobre os corpos dos indivíduos.

A autora, em interessante ponderação, chama a atenção para a negligência do corpo biológico, por vezes praticada por antropólogos da saúde:

- em parte, pelas limitações técnicas e da tradição epistemológica da disciplina;

- em parte porque sua preocupação tem sido trazer o significado social, político, econômico e cosmológico da doença para a atenção do mundo médico;

- porque os aspectos biológicos e físicos do corpo sensível não podem ser vistos ou comentados assim facilmente pela pesquisa sociocultural.

Estudando o nervoso (como diz o povo, ou a histeria e, às vezes, o estresse, como dizem os médicos), pude perceber ainda que ele evidencia o dilema histórico, ainda vivido pela medicina, resultante de sua incapacidade de lidar com certas situações e casos, assim como da onipotência com que tenta revestir sua prática. Dilema esse que representa uma relação dialética entre o novo - no caso de Hipócrates, o cientifico - e o velho, a alma animal, indomada e por vezes cruel. Representa ainda os limites paradigmáticos propostos pela medicina para o ser humano em confronto com as infinitas possibilidades que ele próprio descobre diuturnamente. Na verdade, evidencia-se aí apenas uma situação de confronto entre o que consegue abordar e resolver com aquilo que the é estranho, por fugir dos seus modelos explicativos e de sua racionalidade habitual.

Hoje, tal como à época hipocrática, a medicina (vista por si mesma como uma profissão resolutiva), toda vez que carece de proposições resolutivas toma o problema como objeto do campo metafísico; deslocando-o para outra dimensão, exime-se da necessidade, que ela mesma se impôs, de resolvê-lo. Tal é o caso dos nervos, que hoje não encontra mais espaço nos textos médicos, exceto naqueles fortemente influenciados pela antropologia (e. g. Costa, 1983c, 1987d).

Os casos entrevistados mostraram aspectos interessantes do ataque e do sofrimento dos nervos, permitindo uma leitura e uma interpretação que diferem daquelas propostas para o diagnóstico médico de histeria, muito embora sua apresentação per- 
mita tal diagnóstico. A interpretação clássica da histeria, reforçada pela psicanálise, tem seu fulcro na sexualidade e resulta, na prática da atenção às doentes, em sua redução ao âmbito meramente genital da doença, o que, neste ponto, iguala a compreensão médica desse sofrimento à metáfora ilhoa de nervo como falta de pênis, a qual, se não foi refutada, ao menos não foi evidenciada nos relatos das pacientes. A sexualidade entronada por essas visões não aparece nos relatos espontâneos das pacientes e, a menos que se force, também aparece pouco na interpretação fornecida por elas.

Ao cabo desta pesquisa, e por ela autorizada, faço uma leitura de nervos que se aproxima mais daquelas como a de Scheper-Hughes e a de Rozemberg, que entendem que nervos fala de outras coisas além da sexualidade. Fala da pobreza dos relacionamentos, de pobreza e de miséria materiais, de incapacidades, de desejos insatisfeitos, de dificuldades, de opressão (Scheper-Hughes, 1992d; Rozemberg, 1994c; Chiozza, 1987d).

Uma das dificuldades de lidar com os nervos talvez resulte da impossibilidade de reduzi-lo a um modelo de atendimento no qual a imagem que os agentes terapêuticos têm dos pacientes apenas reflete experiências de enfermidade que se ajustam às estruturas cognitivas, aos estereótipos a ele pertinentes. Como a experiência dos nervos foge aos propostos pela instituição biomédica, esta não só tem dificuldades de prover subsídios para o seu atendimento adequado como tende a ignorar, reduzir e escamotear os seus significados.

Por isso, talvez seja prudente seguir o senso popular e desistir da aproximação entre nervos e histeria, pois ficou patente que a conformação dada pela cultura local aos sintomas e, principalmente, aos significados da síndrome dos nervos, quase nada tem em comum com aquela, além da apresentação freqüentemente espetacular.

Considerando que compreender é pegar o sentido, captar o significado de alguma coisa, nervos, para ser compreendido, exige a colocação de um ser humano diante de outro. Quer dizer, um sujeito que conheça o significado diante de outro que traga consigo o significante. Ou seja, requer muito mais que o propalado humanismo da medicina.

Para atender a tal condição, seria necessário que o médico se colocasse diante do sofredor como uma pessoa passível também de eventuais ataques de nervos e, ainda, detentor, ele próprio, do mesmo código de significados culturais que a crise de nervos tem para os pacientes. Porém, o ensino médico, especialmente no chamado currículo oculto, promove justamente o contrário: a desumanização do médico, afastando-o cada vez mais dos pacientes e, simultaneamente, promovendo sua aproximação com a doença e com a fisiopatologia (Boletim da Organização Panamericana, 1995). ${ }^{2}$

Neste panorama, poderia parecer desanimador pensar na possibilidade de resolver, pela via da medicina, um problema como o dos nervos ou outros similares. Porém, esforços vêm sendo feitos para quebrar o isolamento dessa disciplina, pela humanização de sua prática e pelo aporte de conteúdos de outras áreas do conhecimento, como as ciências sociais e humanas, no domínio antes inexpugnável do conhecimento e das práticas médicas. Assim, acertado é o comentário de Schepper-Hughes: 
Mas a clínica, como considerou Foucault, pode ser isolada, fechada do mundo externo e do mundo da experiência dos pacientes. Ou eles podem prover um espaço onde novos caminhos de acessar e responder à miséria humana são abertos. Desde esse indistinto panorama de necessidades humanas, algumas vozes se levantam em dor e fome, protestando sua própria impotência. Uma dessas vozes é a dos nervos. Nós podemos concluir perguntando o que a medicina pode transformar, além dos fins humanitários que ela esposa, o que poderia ver no sofrimento que entra a clínica como uma expressão da trágica experiência do mundo. Nós podemos ter a base para a liberação da medicina, uma nova medicina, como uma nova teologia, fundada na esperança. (Schepper-Hughes, 1992:215) (grifo do autor)

Nervos, histeria, piti... Como quer que seja chamado, o tema é intrigante e, por certo, ainda será assunto de muita dissertação, tanto quanto de descaso. Preferindo a primeira possibilidade, evoco as palavras de outra autora para exprimir o que sinto neste ponto do trabalho, quando a fase que o liga a uma proposta acadêmica está por se encerrar:

Não se trata de concluir, fechar. Se este livro levantou mais questões para o leitor do que aquelas que ele se colocava no início da leitura, ele atingiu seu objetivo. Até mesmo a questão de saber se a histeria é, ou não, uma doença não foi respondida. O certo é que ela se refere a todos nós. O médico não pode ficar indiferente à histeria. Ele pode trazer-lhe uma grande contribuição. E, ao mesmo tempo, ao seguir a histeria, ele mesmo pode ganhar muito. Tratemos também do amor e da morte, da mentira e da verdade. Uma verdade que não pode ser saciada, e que deixa tudo a desejar. (Israël, 1995c:326) (grifo meu)

\section{NOTAS}

1 O paradigma cartesiano se funda na famosa dicotomia corpo-mente e na consideração metafórica do corpo humano como máquina.

2 Carapinheiro (1993) chama a esse processo de cinismo crescente, presente no processo de formação médica. 